\title{
Anti-Müllerian hormone and polycystic ovary syndrome: a mountain too high?
}

\author{
Laura Pellatt, Suman Rice and Helen D Mason \\ Basic Medical Sciences, St George's, University of London, Cramner Terrace, London SW17 ORE, UK \\ Correspondence should be addressed to L Pellatt; Email: Ipellatt@sgul.ac.uk
}

\begin{abstract}
Anti-Müllerian hormone (AMH) was initially thought to be produced solely by the foetal male during sexual differentiation to promote regression of the Müllerian ducts. Over the last decade, however, a new and interesting role has emerged for AMH in the ovary. In human ovaries, AMH is produced by granulosa cells from 36 weeks of gestation until menopause, with the highest expression being in small antral follicles. AMH production gradually declines as follicles grow; once follicles reach a size at which they are dominant, it has largely disappeared. Its removal from these larger follicles appears to be an important requirement for dominant follicle selection and progression to ovulation as AMH has an inhibitory role in the ovary, reducing both primordial follicle initiation and follicle sensitivity to FSH by inhibition of aromatase. It is for this reason that AMH is a focus of interest in polycystic ovary syndrome (PCOS). Serum levels are doubled, and granulosa cell production is greatly increased. Interestingly, there appear to be two groups of women with PCOS who can be distinguished by their AMH level: one group consists of those who have high levels which do not reduce with treatment and who respond less well to induction of ovulation, and a second group consists of those in whom the level is less elevated and reduces on treatment and who seem to respond rather better. Understanding the reason for the raised AMH in PCOS may give clues as to the mechanism of anovulation. To conclude, AMH appears to have a major inhibitory role during folliculogenesis, which may contribute to anovulation in PCOS.

Reproduction (2010) 139 825-833
\end{abstract}

\section{Introduction}

Anti-Müllerian hormone (AMH), also known as Müllerian-inhibiting substance, is a member of the transforming growth factor- $\beta$ (TGF $\beta$ ) superfamily, which includes more than 35 structurally related peptides including activins, inhibins, bone morphogenetic proteins (BMPs) and growth differentiation factors. Many of these are involved in the reproductive function of both sexes (Itman et al. 2006, Knight \& Glister 2006). The AMH gene is located on chromosome 19 (Cohen-Haguenauer et al. 1987, Cate et al. 1990) and encodes a 140 kDa dimeric glycoprotein. AMH is synthesised as a pro-hormone, which undergoes cleavage at the site of action to generate a biologically active C-terminal fragment (Pepinsky et al. 1988, Wilson et al. 1993, Rey et al. 2003).

Members of the TGF $\beta$ superfamily exert their effects through serine/threonine kinase receptors. AMH acts on its own specific type II receptor, AMHR2 (Imbeaud et al. 1995, Visser et al. 1995), to signal through a BMP-like pathway, recruiting one of the type I receptors; ALK 2, 3 or 6. Downstream signalling of the AMH receptor involves cytoplasmic effectors known as receptor-related SMAD proteins (R-Smads 1, 5 and 8) and a common SMAD4 protein (Visser 2003). Once AMH binds to
AMHR2, the type I receptor becomes recruited forming a receptor complex. This results in activation of the type I receptor, which causes phosphorylation of R-Smads. These proteins bind to the common SMAD4 protein, resulting in translocation of the complex into the nucleus and binding directly to the DNA to regulate gene expression or interacting with other DNA-binding proteins (Massague \& Wotton 2000).

AMHR2 is essential for signalling was demonstrated by the fact that its disruption in mice caused persistence of the Müllerian ducts (Mishina et al. 1996, di Clemente et al. 2003). In humans, mutations of either the $A M H$ or the $A M H R 2$ gene are the cause of persistent Müllerian duct syndrome (Josso et al. 2005).

\section{Ovarian AMH}

Bioactive AMH was first detected in granulosa cells in the 1980s (Vigier et al. 1984). It was later reported that $\mathrm{AMH}$ was produced from 36 weeks of gestation in human GCs (Rajperts-de Meyts et al. 1999) and was expressed until menopause. Many studies followed demonstrating $\mathrm{AMH}$ expression in rats (Ueno et al. 1989, Baarends et al. 1995), mice (Munsterberg \& Lovell-Badge 1991), sheep (Sweeney et al. 1997) and 
human (Weenen et al. 2004, Stubbs et al. 2005, Modi et al. 2006) ovaries using in situ hybridisation or immunostaining. It is still unclear precisely when during folliculogenesis AMH expression begins with the studies on primordial follicles producing equivocal results (Stubbs et al. 2005, Modi et al. 2006), but it is clear that the highest expression of $\mathrm{AMH}$ is found in preantral and small antral follicles. The latter being those involved in FSH-dependent cyclic recruitment (Ueno et al. 1989, Baarends et al. 1995, Weenen et al. 2004). After selection, the level of expression gradually declines in the mural GCs with the AMH-positive staining becoming localised to the cumulus GCs (Munsterberg \& Lovell-Badge 1991). Direct measurements of AMH protein production by human GCs and follicular fluid in 2007 confirmed that the highest concentrations were in small antral follicles and became very low or undetectable in follicles $\geq 10 \mathrm{~mm}$ (Pellatt et al. 2007a), as shown in Fig. 1. The cessation of production of $\mathrm{AMH}$ from these follicles suggests that this is an important requirement for selection of the dominant follicle.

Neither AMH staining nor $A M H$ mRNA expression was observed in oocytes, corpus luteum, atretic follicles or theca cells in mice, rats or human ovaries (Ueno et al. 1989, Baarends et al. 1995, Weenen et al. 2004, Modi et al. 2006), confirming that the GCs are the only source of $\mathrm{AMH}$ in the ovary.

AMHR2 was shown to have a similar pattern to $A M H$ mRNA expression in rodent follicles (Baarends et al. 1995), in which expression of both was colocalised in the GCs of preantral and small antral follicles. Interestingly, the mRNA for the AMH receptor was also found in the theca from a range of follicle sizes as well as in GCs and granulosa-luteal cells (GLCs) from human ovaries
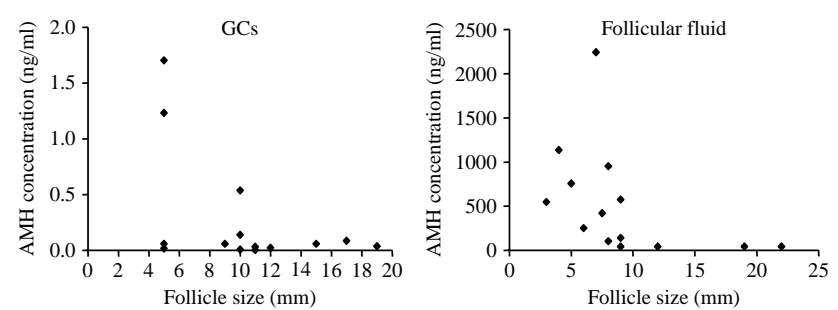

Figure $1 \mathrm{AMH}$ concentration in GC and follicular fluid from normal ovaries: left panel: $\mathrm{AMH}$ production was measured in the medium conditioned by GCs from 14 follicles (range 4-19 mm) collected from 12 individual patients. Levels of AMH declined as the follicle size increased with very low or undetectable levels of $\mathrm{AMH}$ in follicles $>10 \mathrm{~mm}$. Right panel: follicular fluid aspirated from 18 follicles from eight patients. Follicles ranged from 3 to $22 \mathrm{~mm}$ in diameter. The concentration of $\mathrm{AMH}$ was highest in the smallest follicles, then decreased to low or undetectable in follicles $>9 \mathrm{~mm}$. (Graph reproduced, with permission, from Pellatt L, Hanna L, Brincat $\mathbf{M}$, Galea R, Brain H, Whitehead S \& Mason H 2007 Granulosa cell production of anti-Müllerian hormone is increased in polycystic ovaries. Journal of Clinical Endocrinology and Metabolism 92 240-245. Copyright 2007, The Endocrine Society).
(Ingraham et al. 2000, Hanna et al. 2006). The effects of AMH on theca function are yet to be determined, but this poses the possibility of a new signalling pathway between granulosa and theca in the developing follicle.

\section{A reliable marker of ovarian function?}

In females, $\mathrm{AMH}$ has been heralded as a marker of ovarian ageing and reserve in humans (Van Roojj et al. 2002, de Vet et al. 2002). In mice, the higher production of $\mathrm{AMH}$ by small antral follicles reflected the remaining follicle pool (Kevenaar et al. 2006). Women of $<25$ years of age had higher serum AMH concentrations than those aged 35 years and above (Piltonen et al. 2005), and when women were followed longitudinally for a period of between 1 and 7 years, there was a decrease in serum $\mathrm{AMH}$ levels, with levels becoming undetectable when menopause was reached (Piltonen et al. 2005).

It has also been suggested that AMH may be a better predictor for successful IVF treatment and oocyte maturation than traditional markers (Muttukrishna et al. 2005, Silberstein et al. 2006, La Marca et al. 2007). A lower serum AMH concentration preceding or during assisted reproductive techniques was strongly associated with reduced oocyte yield and low oocyte quality (Silberstein et al. 2006, La Marca et al. 2007). This might be expected if serum AMH concentrations produced by the small follicles indirectly reflect the remaining follicle pool. Ironically, the opposite appears to be true for successful treatment of infertility in women with polycystic ovary syndrome (PCOS), in that those who had the highest concentrations of AMH seemed to respond less well. This is discussed in detail below. In terms of predicting outcome, a recent systematic review of possible predictors of outcome of IVF has found that any tests of ovarian reserve, including $\mathrm{AMH}$, had only 'modest-to-poor' predictive properties and were unsuitable as a basis for clinical decision making (Broekmans et al. 2006). Understanding the importance of $\mathrm{AMH}$ in normal ovarian function may assist in improving treatment regimens and in improving success rates in the future; however, it appears that at least at the moment, these tests are insufficiently robust as a basis for clinical decision making.

\section{Function of AMH in the normal ovary}

Some of the most informative studies examining $\mathrm{AMH}$ action in the ovary have been performed by knocking out $\mathrm{AMH}$ or its receptor. $\mathrm{AMH}$ knockout (AMHKO) mice (Durlinger et al. 1999, 2001, 2002) are fertile, but have an increase in the number of growing follicles resulting in depletion of the primordial pool and early cessation of ovulation (Durlinger et al. 1999): an effect which was reversed by culture of ovaries from 2-day-old mice with AMH (Durlinger et al. 2002). These results were confirmed by culture of mouse AMHR2-null or 
wild-type ovaries beneath the chorioallantoic membrane of chick embryos ('in ovo'). In this position, the pieces of tissue become vascularised thereby preventing the normal loss of follicles which occurs in culture. There was an increase in follicle growth compared to wild-type in those pieces lacking AMH receptor (Gigli et al. 2005).

In human tissue, the picture is rather less straightforward. In cultured human ovarian cortical biopsies, AMH treatment $(100 \mathrm{ng} / \mathrm{ml})$ reduced primordial follicle growth compared to untreated tissue in one study (Carlsson et al. 2006), whereas in another study, $\mathrm{AMH}$ actually increased the numbers of primordial follicles growing (Schmidt et al. 2005). The latter study used a higher dose of $\mathrm{AMH}$, and the tissue was previously cryopreserved which may account for the difference.

In an effort to clarify the stage of follicle at which AMH may be able to act, we looked for the presence of AMHR2 in individual preantral human follicles and found that it was rarely expressed (Rice et al. 2007). This indicates that $\mathrm{AMH}$ may not have a role at this stage of follicle development in humans. The expression of AMHR2 in rodent preantral follicles (Baarends et al. 2005) and the effect by AMH observed by McGee et al. (2001) on preantral growth indicate that AMH acts on its receptor in these small follicles in the rodent. This suggests that there is a species difference in the expression of AMHR2.

In antral follicles, the overall effect of $\mathrm{AMH}$ is to reduce follicle sensitivity to $\mathrm{FSH}$. A number of in vitro studies have demonstrated similar findings, in that FSH-stimulated follicle growth was inhibited by the addition of $\mathrm{AMH}$. In rat GCs, FSH- and cAMP-stimulated aromatase activity was significantly reduced after $\mathrm{AMH}$ treatment (di Clemente et al. 1994). In the same report, $\mathrm{AMH}$ reduced aromatase mRNA expression in cAMPstimulated cells and also reduced $\mathrm{LH}$ receptor mRNA expression in porcine GCs stimulated with FSH (di Clemente et al. 1994). Even in the low FSH environment of the AMHKO mouse, there was an increase in the number of growing follicles compared to wild-type littermates (Durlinger et al. 2001). An inhibitory effect of $\mathrm{AMH}$ on $\mathrm{FSH}$-stimulated aromatase mRNA expression and oestradiol $\left(\mathrm{OE}_{2}\right)$ production has also been shown in human GLCs (Grossman et al. 2007). Our preliminary data in humans support these reports, in that $\mathrm{AMH}$, in the presence of $\mathrm{FSH}$ or $\mathrm{LH}$, significantly reduced aromatase mRNA expression and activity in GCs from small $(4-9 \mathrm{~mm})$ and large $(\geq 10 \mathrm{~mm})$ follicles respectively (Pellatt et al. 2007b). These studies collectively demonstrate an inhibitory role of $\mathrm{AMH}$ in antral follicle growth, and it can be envisioned that high concentrations of $\mathrm{AMH}$ in small antral follicles would hold back FSH responsiveness and steroidogenesis and acquisition of $\mathrm{LH}$ receptors until the time of follicle selection. By the time the intercycle rise in FSH has occurred, $\mathrm{AMH}$ production ceases, concentrations fall and the follicle is 'released' to produce $\mathrm{OE}_{2}$.
Intriguingly, the factor causing inhibition of $\mathrm{AMH}$ production in these selected follicles remains unknown and, in our hands at least, it is not the obvious candidate, FSH itself (Pellatt et al. 2007a). Discovery of this inhibitor is important as it may provide a clue as to why $\mathrm{AMH}$ production is high in PCOS.

There is one other important question which arises regarding the role of $\mathrm{AMH}$ in these small follicles. It is well described that $\mathrm{AMH}$ causes regression of the Müllerian duct by inducing cellular apoptosis (Roberts et al. 1999). It is therefore interesting to speculate as to why the high concentrations in small follicles are not similarly damaging. In the Müllerian duct, atresia occurs in a pattern from cranial to caudal following the AMHR2 gradient. We have previously shown the presence of the receptor in both theca and granulosa of small healthy follicles, so why do these follicles similarly not undergo atresia due to cellular apoptosis? Is it possible that in ovarian cells the requisite intermediary pathways are absent? The only study to date to our knowledge investigating the effect of $\mathrm{AMH}$ on ovarian cell growth did show that it was in fact decreased (Kim et al. 1992), and this is hard to reconcile with the known increase in granulosa and theca cell division which occurs in small follicles. Figure 2 illustrates how AMH may modulate ovarian follicle development. Research into the role of ovarian $\mathrm{AMH}$ and the expression pattern of the receptor clearly needs to address this issue, particularly in light of the high concentrations found in PCOs.

\section{AMH and PCOS}

PCOs are characterised by an increase in follicle number, and this increase has been shown to occur at the earliest stages. The previously demonstrated ability of $\mathrm{AMH}$ to alter early follicle growth therefore made it a candidate for causing this change. In order to investigate this possibility, the expression of $\mathrm{AMH}$ in fixed stained sections of PCOs from anovulatory or ovulatory women was determined by immunostaining (Stubbs et al. 2005). The percentage of positively stained primordial and transitional follicles from anovulatory ovaries was significantly lower than from normal and ovulatory PCOs (ovPCOs); however, the intensity of staining in the preantral and antral follicles was similar among all three groups (Stubbs et al. 2005). This suggests that the absence of AMH in anovulatory PCOs (anovPCOs) at the early stage of follicle development may allow for an increased number of follicles to initiate growth. It is perhaps the later appearance of theca that may increase the production of $\mathrm{AMH}$ in these follicles, but until the factors controlling $\mathrm{AMH}$ production are determined, this will remain speculation.

$\mathrm{AMH}$ has been shown to be two- to three-fold higher in serum from women with PCOS than in women with normal ovaries (Fallat et al. 1997). This was initially thought to be due to the increase in the number of small 


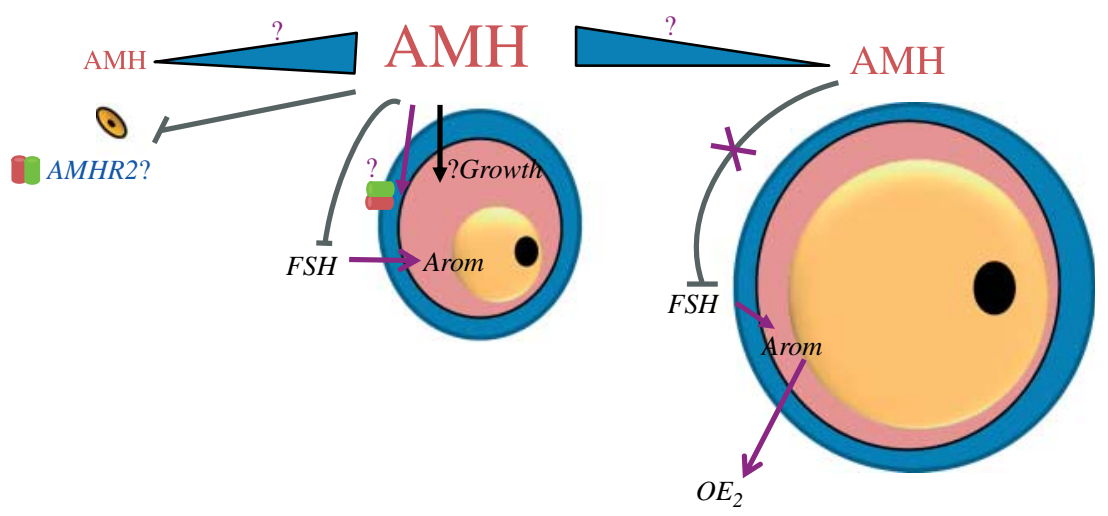

Figure $2 \mathrm{AMH}$ as a regulator of normal follicle growth and development: $\mathrm{AMH}$ production in preantral follicles is variable, but has been detected from the primary stage onwards. It is unclear whether preantral follicles express AMHR2. AMH production by surrounding larger follicles is thought to inhibit primordial follicle initiation by a paracrine action. AMH production by granulosa cells (pink layer) increases to the small antral stage by an unknown mechanism. AMH may 'fine tune' follicle development by inhibiting early maturation of these follicles. It may reduce follicle sensitivity to $\mathrm{FSH}$, thereby inhibiting aromatase mRNA expression and activity. The effects on cell proliferation are uncertain, but it does not clearly have the apoptotic effect seen in the Müllerian duct during differentiation. AMHR2 has been detected in theca (blue layer) from a range of follicle sizes, but its actions are unknown. As the follicles develop and grow, AMH levels decline, but the causative factor/s remains to be discovered. The decrease in $\mathrm{AMH}$ then releases the inhibitory effect, allowing these larger follicles to become responsive to FSH, and stimulating aromatase and oestradiol production.

antral follicles; however, in 2007, we demonstrated that $\mathrm{AMH}$ production was on average 75 times higher per granulosa cell from anovPCOs than from cells from normal ovaries (Fig. 3). Similarly, concentrations of AMH were found to be five times higher in follicular fluid from unstimulated follicles from women with anovulatory PCOS compared to women who were ovulatory (Das et al. 2008). In a further study, the serum concentration of $\mathrm{AMH}$ correlated with the severity of symptoms, with again the ovulatory group having lower concentrations than those who were equally hyperandrogenic but anovulatory (Piouka et al. 2009). Interestingly, follicle number only added $5.3 \%$ to the variance in the concentration of $\mathrm{AMH}$. The fact that raised $\mathrm{AMH}$ production was an intrinsic property of granulosa cells in PCOs was later confirmed by the finding of raised levels of $A M H$ mRNA in these GCs, even after stimulation for IVF (Catteau-Jonard et al. 2008). Together, these studies demonstrate that the increase in $\mathrm{AMH}$ concentration is largely due to the increase in production of $\mathrm{AMH}$ by each follicle and not just a consequence of an increase in follicle number.

The cause of the increased AMH production in PCOS is unknown; however, increased concentrations may be a consequence of other factors altered in PCOS, the most obvious being androgen production. Evidence to support this comes from the studies showing that in serum, AMH has been positively correlated to androgen levels (Pigny et al. 2003, Laven et al. 2004, Eldar-Geva et al. 2005). Women with hyperandrogenism and PCO had higher serum concentrations of AMH than women with PCO and normal androgen concentrations (Eldar-Geva et al. 2005). In addition, androgen production per theca cell was equally increased in anovPCOs and ovPCOs
(Gilling-Smith et al. 1994); however, the total number of follicles found in the anovulatory ovary is higher resulting in increased total androgen (Mason 2001). Therefore, this may not only explain the higher $\mathrm{AMH}$ concentrations found in all PCOs, but also explain the significantly higher production of AMH by cells from the anovulatory ovaries. The results of a very recent study, however, rather contradict this idea. Although at the beginning of the study, there was a direct correlation between $\mathrm{AMH}$ and androgen levels in a group of women with PCOS, after 6 months of androgen suppression with dexamethasone, the $\mathrm{AMH}$ concentration remained unchanged (Carlsen et al. 2009). It is possible, however, that the concentration of androgen within the ovary is the determining factor. It is interesting to note that in the

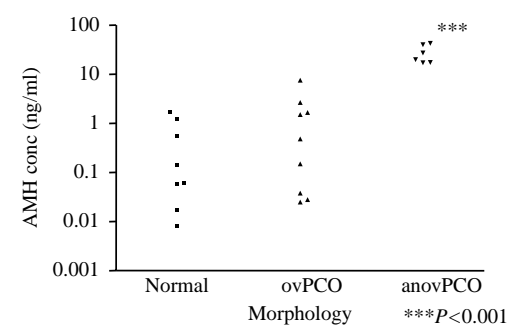

Figure 3 Comparison of $\mathrm{AMH}$ concentration from normal ovaries, ovPCOs and anovPCOs: AMH production was measured in the medium conditioned by GCs isolated from follicles ranging from 2 to $10 \mathrm{~mm}$ in size from normal ovaries $(n=7)$, ovPCOs $(n=9)$ and anovPCOs $(n=5)$. AMH production was significantly different between normal, ovPCOs and anovPCOs. Mean concentration of AMH in GCs from anovPCOs was 75 times higher than the mean for normal ovaries. Note the log scale. (Graph reproduced, with permission, from Pellatt L, Hanna L, Brincat M, Galea R, Brain H, Whitehead S \& Mason H 2007 Granulosa cell production of anti-Müllerian hormone is increased in polycystic ovaries. Journal of Clinical Endocrinology and Metabolism 92 240-245. Copyright 2007, The Endocrine Society). 
testis, androgens actually inhibit AMH production (Rey et al. 1993), so a different control mechanism would have to be present in the ovary for androgens to cause the rise seen in PCO.

Another candidate for the cause of the increase in $\mathrm{AMH}$ in PCOS is insulin. Hyperinsulinaemia is known to affect anovulatory women more than ovulatory women (Conway \& Jacobs 1993), and falling insulin concentrations do correlate with the return of ovulatory cycles (Dunaif et al. 1988). La Marca et al. (2004a) found no correlation between serum $\mathrm{AMH}$ and androgen levels, but did observed a direct correlation between $\mathrm{AMH}$ and insulin insensitivity. Insulin has been shown to enhance gonadotrophin-stimulated steroid production in GCs and theca (Willis et al. 1996); therefore, the raised AMH concentrations may be secondary to an effect of insulin on androgen levels. Although this is a possible cause, other studies have failed to find a direct correlation between insulin and $\mathrm{AMH}$ concentrations (Pigny et al. 2003, Eldar-Geva et al. 2005), and even when insulin levels have reduced with treatment, a fall in serum $\mathrm{AMH}$ has not followed directly (Bayrak et al. 2007, Carlsen et al. 2009). It is possible that there is an intrinsic over-expression of the $A M H$ gene causing the raised production of the protein in the PCO or that the currently unknown factor driving the androgen production also increases $\mathrm{AMH}$. Discovering the answers to these questions may have important implications for the treatment of this condition.

\section{AMH and response to treatment in PCOS}

One interesting and important finding from our study was that women with PCOs could be clearly divided into ovulatory or anovulatory by identifying whether or not their GCs were 'low' or 'high' AMH producers. In women with $\mathrm{PCO}$ but regular cycles, AMH production was still significantly higher than normal; however, GCs from anovPCOs produced on average 18 times more AMH than GCs from ovPCOs (Fig. 3). The results were tightly grouped with no overlap (Pellatt et al. 2007a). Is it possible therefore that in order to begin ovulating the GC production of $\mathrm{AMH}$ in follicles in anovPCOs has to be greatly reduced? A partial answer to this question has come from the results of some recent publications regarding response to treatment in women with PCOS. One study showed that pre-treatment of $\mathrm{AMH}$ was a reliable predictor of reproductive response to weight loss (Moran et al. 2007), in that although the degree of weight loss was similar, it was only those women with lower $\mathrm{AMH}$ who responded with an increase in the number of ovulatory cycles. This was followed by an investigation of the reverse phenomenon, i.e. whether improvement in reproductive function was accompanied by reduced AMH (Thomson et al. 2009). Weight loss did improve reproductive function, but again only in those patients who already had significantly lower serum AMH at the start and in neither group did the weight loss result in a reduction in $\mathrm{AMH}$. We are therefore hypothesising that in this group of women with PCOS and chronic anovulation, the high GC production of $\mathrm{AMH}$ does not reduce and is preventing a response to weight loss treatment. It is only in those with less elevated AMH that the ovary can be coaxed into overcoming its inhibitory effects (Fig. 4).

Is this hypothesis supported by the results of other treatments for induction of ovulation? The data are rather scarce; however, in one study, the response to clomiphene citrate in obese patients with PCOS was again dependent on initial AMH concentration (El-Halawaty et al. 2007). Unfortunately, AMH response during treatment was not measured in this study. With regards to metformin treatment, there are a number of studies that have correlated reduced $\mathrm{AMH}$ with responsiveness; however, the $\mathrm{AMH}$ measurement has been made during or after treatment as opposed to correlating pretreatment levels with subsequent response.

This hypothesis may appear to be contradicted by the number of studies indicating that high $\mathrm{AMH}$ is a positive predictor of outcome of IVF; however, the majority of these studies have not focussed on women with PCOS and involve women with different or non-specified ovarian morphology. When the concentrations of $\mathrm{AMH}$ were measured in follicular fluid collected at the time of oocyte retrieval for IVF only from women with PCOs, the results were very interesting. Although again $\mathrm{AMH}$ was higher compared to ovulatory women, the concentrations in both small and large follicles were found to be lower in those women who began a pregnancy (Desforges-Bullet et al. 2010). This indicates that even following a stimulation protocol, it is those women with PCOS producing the relatively lower levels of AMH who have the best outcome.

Although metformin is now one of the most common treatments for PCOS, to our knowledge, there are no studies in which the initial concentration of $\mathrm{AMH}$ has been correlated with response to treatment, but it is clear that $\mathrm{AMH}$ concentrations do fall during treatment, even if this does take some time. Certainly over the course of a single week, metformin did not reduce the serum AMH level despite there being a reduction in antral follicle number (Bayrak et al. 2007). This is not surprising given that in other studies it was not until after 4, 6 or 8 months of metformin treatment that $\mathrm{AMH}$ levels fell (Fleming et al. 2005). It was assumed that the time taken reflected the growth of a new cohort of follicles from the earliest stages, and that these follicles had developed in a partially normalised endocrine environment. One problem with interpreting $\mathrm{AMH}$ levels in serum is that it is only a reflection of the total ovarian output, and this will depend on both the follicle number and size distribution given that production is highest in the small antral follicles. 


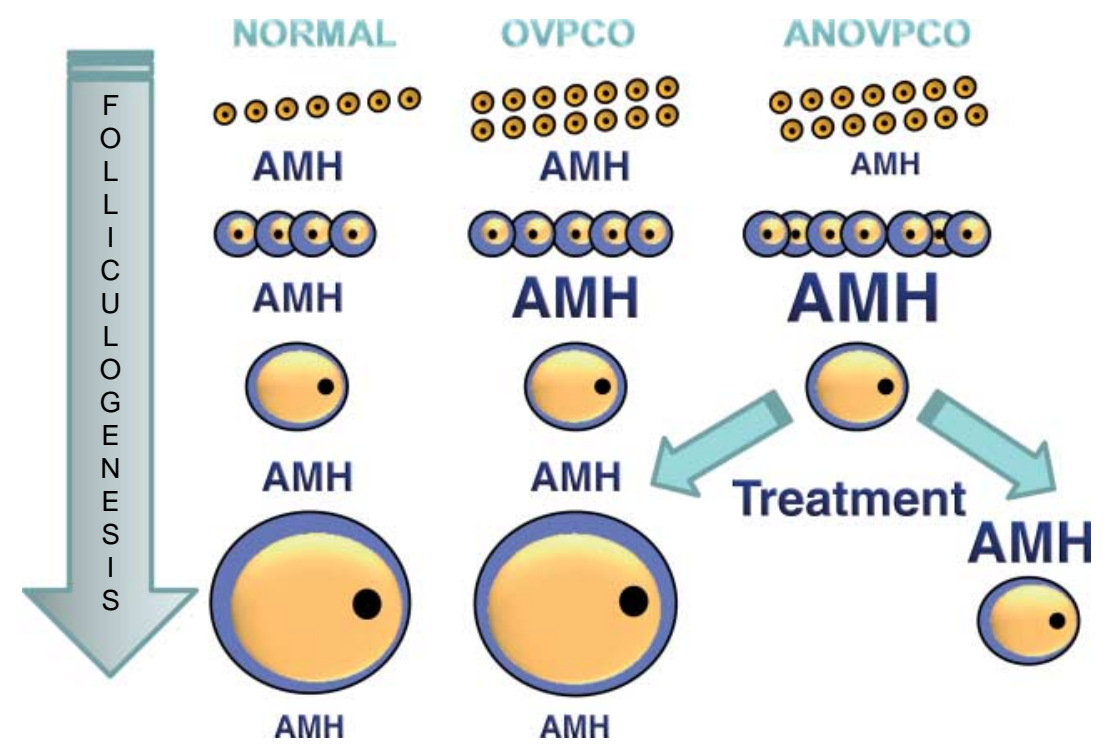

Figure 4 Hypothesis of the effects of $\mathrm{AMH}$ on follicles in polycystic ovaries: both ovulatory and anovulatory polycystic ovaries increased the numbers of preantral follicles than normal ovaries and more of these ovaries progress to antral stages in both; however, anovulatory ovaries contain the most. A lower percentage of both primordial and transitional follicles stained positive for AMH in anovPCOs than in the two ovulatory groups which may explain the excess numbers of antral follicles found in the latter, in that there is a reduced AMH 'break' on progression. Granulosa cell AMH production increases rapidly as the follicles become antral in all groups, but in the ovulatory and anovulatory polycystic ovaries, the levels increase several fold and $\sim 75$ fold above normal respectively. In the two ovulatory groups as the dominant follicle is selected, AMH levels fall and are virtually undetectable in the pre-ovulatory follicle. In the anovulatory women undergoing treatment, e.g. by weight loss, either the AMH reduces and ovulatory cycles resume, or it is resistant to treatment, remaining high and exerting a break on aromatase and follicle growth.

One of the most reliable methods of induction of ovulation in PCOS is FSH treatment. Women treated with recombinant human FSH to induce ovulation had lower serum concentrations of $\mathrm{AMH}$ after treatment (La Marca et al. 2004b), again indicating that reducing $\mathrm{AMH}$ is an essential part of the response. Indeed, it has generally been anticipated that FSH would be the factor responsible for the reduction in $\mathrm{AMH}$ production seen following follicle selection in natural cycles. Indeed, we observed a significant reduction in concentrations of $\mathrm{AMH}$ protein in the conditioned medium from GCs from PCOs which had been treated with FSH. Surprisingly, however, this was not seen in cells from normal ovaries (Pellatt et al. 2007a). Curiously, acute stimulation with FSH (24 h) in women with PCOS had no effect on serum $\mathrm{AMH}$ concentrations (Wachs et al. 2007). An earlier in vitro study in mice demonstrated a reduction in $\mathrm{AMH}$ in response to $\mathrm{FSH}$ and $\mathrm{OE}_{2}$ (Baarends et al. 1995). It may be possible that it is not $\mathrm{FSH}$ per se that is affecting $\mathrm{AMH}$ levels, but it is the $\mathrm{FSH}$-stimulated $\mathrm{OE}_{2}$ production, and this effect may take a little longer to become evident. In support of this, a number of groups have shown a negative correlation between $\mathrm{OE}_{2}$ and serum $\mathrm{AMH}$ concentrations in women with PCOS (Fallat et al. 1997, La Marca et al. 2004a); however, $\mathrm{OE}_{2}$ production by the follicle is the end point of many processes and factors, and again these results are difficult to interpret. It seems that there is a fine balance between $\mathrm{AMH}$ production and follicle sensitivity to $\mathrm{FSH}$, which will need to be examined further. If this was the case, then it could be seen that those women with very high intra-follicular concentrations of $\mathrm{AMH}$ may be prevented from inducing the aromatase and subsequently the $\mathrm{OE}_{2}$ which is the very important thing required to reduce the $A M H$. One further piece of information which adds to the puzzle is that $\mathrm{AMH}$ itself was able to stimulate FSH $\beta$-subunit mRNA expression in a pituitary cell line (Bedecarrats et al. 2003). It is difficult to reconcile this with anovulation in PCOS because, if this is the case, why do women with high serum AMH concentrations not have higher FSH levels also? There are clearly a number of research questions which remain to be answered.

\section{Conclusion}

$\mathrm{AMH}$ has an inhibitory role in the ovary, and the increased production by GCs from anovPCOs may therefore contribute to cessation of follicle development. It appears that a decrease in $\mathrm{AMH}$ is an essential part of reproductive response to treatment and that those women with the highest concentrations have the worst outcome. The evidence has led us to hypothesise that there is a subgroup of women with PCOS who have elevated levels of $\mathrm{AMH}$ and who are the most resistant to treatment. $\mathrm{AMH}$ is unlikely to be the sole cause of anovulation, but its effects on aromatase expression and 
$\mathrm{OE}_{2}$ production suggest that it is involved in follicle growth and selection, and that very high concentrations actually prevent the normal process of removal of the AMH 'break' from the follicle. The function and regulation of the production of $\mathrm{AMH}$ in the normal ovary warrant further investigation if we are to unravel the complexities of its action in PCOS.

\section{Declaration of interest}

The authors declare that there is no conflict of interest that could be perceived as prejudicing the impartiality of the research reported.

\section{Funding}

This work was supported by the Wellcome Trust project grant (WT073572MA, 081420/Z/06/Z) to S Rice and H D Mason and the Medical Research Council project grant (G0700916) to H D Mason.

\section{References}

Baarends WM, Uilenbroek JT, Kramer P, Hoogerbrugge JW, van Leeuwen EC, Themmen AP \& Grootegoed JA 1995 Anti-Müllerian hormone and anti-Müllerian hormone type II receptor messenger ribonucleic acid expression in rat ovaries during postnatal development, the estrous cycle, and gonadotrophin-induced follicle growth. Endocrinology 136 4951-4962.

Bayrak A, Terbell H, Urwitz-Lane R, Mor E, Stanczyk FZ \& Paulson RJ 2007 Acute effects of metformin therapy include improvement of insulin resistance and ovarian morphology. Fertility and Sterility $\mathbf{8 7}$ 870-875.

Bedecarrats GY, O'Neill FH, Norwitz ER, Kaiser UB \& Teixeira J 2003 Regulation of gonadotropin gene expression by Müllerian inhibiting substance. PNAS 100 9348-9353.

Broekmans FJ, Kwee J, Hendriks DJ, Mol BW \& Lambalk CB 2006 A systematic review of tests predicting ovarian reserve and IVF outcome. Human Reproduction Update 12 685-718.

Carlsen SM, Vanky E \& Fleming R 2009 Anti-Müllerian hormone concentrations in androgen-suppressed women with polycystic ovary syndrome. Human Reproduction 24 1732-1738.

Carlsson IB, Scott JE, Visser JA, Ritvos O, Themmen APN \& Hovatta O 2006 Anti-Müllerian hormone inhibits initiation of growth of human primordial ovarian follicles in vitro. Human Reproduction 21 2223-2227.

Cate RL, Donahoe RK \& MacLauglin DT 1990 Müllerian-inhibiting substance. In Peptide Growth Factors and their Receptors II, vol 95, pp 179-210. Eds MB Sporn \& AB Roberts. Berlin: Springer-Verlag.

Catteau-Jonard S, Jamin SP, Leclerc A, Gonzales J, Dewailly D \& di Clemente N 2008 Anti-Müllerian hormone, its receptor, FSH receptor and androgen receptor genes are overexpressed by granulosa cells from stimulated follicles in women with polycystic ovary syndrome. Journal of Clinical Endocrinology and Metabolism 93 $4456-4461$.

di Clemente N, Goxe B, Remy JJ, Cate R, Josso N, Vigier B \& Salesse R 1994 Inhibitory effect of AMH upon the expression of aromatase and LH receptors by cultured granulose cells of rat and porcine immature ovaries. Endocrine 2 553-558.

di Clemente N, Josso N, Gouedard L \& Belville C 2003 Components of the anti-Müllerian hormone signaling pathways in gonads. Molecular and Cellular Endocrinology 211 9-14.
Cohen-Haguenauer O, Picard JY, Mattei MG, Serero S, Nguyen VC, de Tand MF, Guerrier D, Hors-Cayla MC, Josso N \& Frezai J 1987 Mapping of the gene for anti-Müllerian hormone to the short arm of human chromosome 19. Cytogenetics and Cell Genetics 44 2-6.

Conway GS \& Jacobs HS 1993 Clinical implications of hyperinsulinaemia in women. Clinical Endocrinology 39 623-632.

Das M, Gillott DJ, Saridogan E \& Djahanbakhch O 2008 Anti-Müllerian hormone is increased in follicular fluid from unstimulated ovaries in women with polycystic ovary sundrome. Human Reproduction $\mathbf{2 3}$ $2122-2126$

Desforges-Bullet V, Gallo C, Lefebvre C, Pigny P, Dewailly D \& Catteau-Jonard S 2010 Increased anti-Müllerian hormone and decreased FSH levels in follicular fluid obtained in women with polycystic ovaries at the time of follicle puncture for in vitro fertilisation. Fertility and Sterility [in press]. DOI:10.1016/j.fertnstert.2009.03.004.

De Vet A, Laven JSE, Jong FH, Themmen APN \& Fauser BCJM 2002 AntiMüllerian hormone serum levels: a putative marker for ovarian ageing. Fertility and Sterility 77 357-362.

Dunaif A, Mandeli J, Fluhr H \& Dobrjansky A 1988 The impact of obesity and chronic hyperinsulinemia on gonadotropin release and gonadal secretion in patients with polycystic ovarian syndrome. Human Reproduction 66 131-139.

Durlinger ALL, Kramer P, Karels B, de Jong FH, Uilenbroek JTJ, Grootegoed JA \& Themmen JPN 1999 Control of primordial follicle recruitment by anti-Müllerian hormone in mouse ovary. Endocrinology 12 5789-5796.

Durlinger ALL, Gruijter MJG, Kramer P, Kavels B, Kumar TR, Matzuk MM, Rose UM, De Jong FH, Uilenbroek JTJ, Grootegoed VA et al. 2001 AntiMüllerian hormone attenuates the effect of follicle-stimulating hormone on follicle development in the mouse ovary. Endocrinology 142 4890-4899.

Durlinger ALL, Visser VA \& Themmen APN 2002 Regulation of ovarian function: the role of anti-Müllerian hormone. Reproduction $\mathbf{1 2 4}$ 601-609.

Eldar-Geva T, Margalioth EJ, Gai M, Ben-Chetrit A, Algur N, ZylberHaran E, Brooks B, Huerta M \& Spitz IM 2005 Serum anti-Müllerian hormone levels during controlled ovarian hyperstimulation in women in polycystic ovaries with and without hyperandrogenism. Human Reproduction 20 1814-1819.

El-Halawaty S, Rizk A, Kamal M, Aboulhassan M, Al-Sawah H, Noah O \& Al-Inany H 2007 Clinical significance of serum concentration of antiMüllerian hormone in obese women with polycystic ovary syndrome. Reproductive Biomedicine Online 15 495-499.

Fallat ME, Cook C, Siow Y, Carrillo A \& Marra M 1997 Müllerian-inhibiting substance in follicular fluid and serum: a comparison of patients with tubal factor infertility, polycystic ovary syndrome, and endometriosis. Fertility and Sterility 67 962-965.

Fleming R, Harborne L, MacLaughlin DT, Ling D, Norman J, Sattar N \& Seifer DB 2005 Metformin reduces serum Müllerian-inhibiting substance levels in women with polycystic ovary syndrome after protracted treatment. Fertility and Sterility 83 130-136.

Gigli I, Cushman RA, Wahl CM \& Fortune JE 2005 Evidence for a role for anti-Müllerian hormone in the suppression of follicle activation in mouse ovaries and bovine ovarian cortex grafted beneath the chick chorioallantoic membrane. Molecular Reproduction and Development 71 480-488.

Gilling-Smith C, Willis DS, Beard RW \& Franks S 1994 Hypersecretion of androstenedione by isolated theca cells from polycystic ovaries. Journal of Clinical Endocrinology and Metabolism 79 $1158-1164$.

Grossman MP, Nakajima ST, Fallat ME \& Siow Y 2007 Müllerianinhibiting substance inhibits cytochrome P450 aromatase activity in human granulosa lutein cell culture. Fertility and Sterility $\mathbf{8 9}$ 1364-1370.

Hanna L, Pellatt L, Rice S, Whitehead S \& Mason HD 2006 Anti-Müllerian hormone (AMH) production by and AMH type II receptor (AMHRII) in normal human ovaries. Presented at the 8th European Congress of Endocrinology, Glasgow, UK. Endocrine Abstracts 11 P687.

Imbeaud S, Faure E, Lamarre I, Mattei MG, di Clemente N, Tizard R, Carre-Eusebe D, Belville C, Tragethon L, Tonkin C et al. 1995 Insensitivity to anti-Müllerian hormone due to a mutation in the human anti-Müllerian hormone receptor. Nature 11 382-388. 
Ingraham HA, Hirokawa $\mathrm{Y}$, Roberts LM, Mellon SH, McGee E, Nachtigal MW \& Visser JA 2000 Autocrine and paracrine Müllerian inhibiting substance hormone signalling in reproduction. Recent Progress in Hormone Research 55 53-67.

Itman C, Mendis S, Barakat B \& Loveland LK 2006 All in the family: TGF- $\beta$ family action in testis development. Reproduction 132 233-236.

Josso N, Belville C, diClemente N \& Picard JY 2005 AMH and AMH receptor defects in persistent Müllerian duct syndrome. Human Reproduction Update 11 351-356.

Kevenaar ME, Meerasahib MF, Kramer P, van de Lang-Born BM, de Jong FH, Groome NP, Themmen AP \& Visser JA 2006 Serum anti-Müllerian hormone levels reflect the size of the primordial follicle pool in mice. Endocrinology 147 3228-3234.

Kim JH, Seibel MM, Maclaughlin DT, Donahoe PK, Ransil BJ, Hametz PA \& Richards CJ 1992 The inhibitory effects of Müllerian-inhibiting substance on epidermal growth factor induced proliferation and progesterone production of human granulosa-luteal cells. Journal of Clinical Endocrinology and Metabolism 75 911-917.

Knight PG \& Glister C 2006 TGF- $\beta$ superfamily members and ovarian follicle development. Reproduction 132 191-206.

Laven JSE, Mulders AM, Visser J, Themmen AP, de Jong FH \& Fauser BCJM 2004 Anti-Müllerian hormone serum concentrations in normoovulatory and anovulatory women of reproductive age. Journal of Clinical Endocrinology and Metabolism 89 318-323.

La Marca A, Orvieto R, Giulini S, Jasonni VM, Volpe A \& De Leo V 2004a Müllerian-inhibiting substance in women with polycystic ovary syndrome: relationship with hormonal and metabolic characteristics. Fertility and Sterility 82 970-972.

La Marca A, Malmusi S, Giulini S, Tamaro LF, Orvieto R, Levratti P \& Volpe A $2004 b$ Anti-Müllerian hormone plasma levels in spontaneous menstrual cycle and during treatment with $\mathrm{FSH}$ to induce ovulation. Human Reproduction 19 2738-2741.

La Marca A, Giulini S, Tirelli A, Bertucci E, Marsella T, Xella S \& Volpe A 2007 Anti-Müllerian hormone measurement on any day of the menstrual cycle strongly predicts ovarian response in assisted reproductive technology. Human Reproduction 22 766-771.

Mason HD 2001 Follicular growth and function. In Polycystic Ovary Syndrome. Ed Roy Homburg. London: Martin Dunitz Ltd.

Massague J \& Wotton D 2000 Transcriptional control by the TGF- $\beta / S m a d$ signaling system. EMBO Journal 19 1745-1754.

McGee EA, Smith R, Spears N, Nachtigal MW, Ingraham H \& Hsueh AJW 2001 Müllerian inhibitory substance induces growth of rat preantral ovarian follicles. Biology of Reproduction 64 293-298.

Mishina Y, Rey R, Finegold MJ, Matzuk MM, Josso N, Cate RL \& Behringer RR 1996 Genetic analysis of the Müllerian-inhibiting substance signal transduction pathway in mammalian sexual differentiation. Genes and Development 10 2577-2587.

Modi D, Bhartiya D \& Puri C 2006 Developmental expression and cellular distribution of Müllerian inhibiting substance in the primate ovary. Reproduction 132 443-453.

Moran LJ, Noakes M, Clifton PM \& Norman RJ 2007 The use of antiMüllerian hormone in predicting menstrual response after weight loss in overweight women with polycystic ovary syndrome. Journal of Clinical Endocrinology and Metabolism 92 3796-3802.

Munsterberg A \& Lovell-Badge R 1991 Expression of the mouse antiMüllerian hormone gene suggests a role in both male and female sexual differentiation. Development 113 613-624.

Muttukrishna S, McGarrigle H, Wakim R, Khadum I, Ranieri DM \& Serhal P 2005 Antral follicle count, anti-Müllerian hormone and inhibin B: predictors of ovarian response in assisted reproductive technology? British Journal of Obstetrics and Gynaecology 112 1384-1390.

Pellatt L, Hanna L, Brincat M, Galea R, Brain H, Whitehead S \& Mason HD 2007 a Granulosa cell production of anti-Müllerian hormone (AMH) is increased in the polycystic ovary. Journal of Clinical Endocrinology and Metabolism 90 240-245.

Pellatt L, Rice S, Brincat M, Galea R \& Mason H 2007b Anti-Müllerian hormone (AMH) inhibits aromatase expression in granulosa cells from human ovaries. Proceedings of the Endocrine Society USA, 89th Annual Meeting, Toronto, Canada. Oral Presentation: 48-4.
Pepinsky RB, Sinclair LK, Chow EP, Mattaliano RJ, Manganaro TF, Donahoe PK \& Cate RL 1988 Proteolytic processing of Müllerian inhibiting substance produces a transforming growth factor- $\beta$-like fragment. Journal of Biological Chemistry 263 18961-18964.

Pigny P, Merlen E, Robert Y, Cortet-Rudelli C, Decanter C, Jonard S \& Dewailley D 2003 Elevated serum level of anti-Müllerian hormone in patients with polycystic ovary syndrome: relationship to the ovarian follicle excess and to the follicle arrest. Journal of Clinical Endocrinology and Metabolism 88 5957-5962.

Piltonen T, Morin-Papunen L, Koivunen R, Perheentupa A, Ruokonen A \& Tapanainen JS 2005 Serum anti-Müllerian hormone levels remain high until late reproductive age and decrease during metformin therapy in women with polycystic ovary syndrome. Human Reproduction 20 $1820-1826$.

Piouka A, Farmakiotis D, Katsikis I, Macut D, Gerou S \& Panidis D 2009 Anti-Müllerian hormone levels reflect severity of PCOS but are negatively influenced by obesity: relationship with increased luteinizing hormone levels. American Journal of Physiology. Endocrinology and Metabolism 296 E238-E243.

Rajperts-de Meyts E, Jorgensen N, Graem N, Muller J, Cate RL \& Skakkebaek NE 1999 Expression of anti-Müllerian hormone during normal and pathological gonadal development: association with differentiation of Sertoli and granulosa cells. Journal of Clinical Endocrinology and Metabolism 84 3836-3844.

Rey R, Lordereau-Richard I, Carel JC, Barbet P, Cate RL, Roger M, Chaussain JL \& Josso N 1993 Anti-Müllerian hormone and testosterone serum levels are inversely related during normal and precocious pubertal development. Journal of Clinical Endocrinology and Metabolism 77 1220-1226.

Rey R, Lukas-Croisier C, Lasala C \& Bedecarras P 2003 AMH/MIS: what we know already about the gene, the protein and its regulation. Molecular and Cellular Endocrinology 211 21-31.

Rice S, Ojha K, Whitehead S \& Mason H 2007 Stage-specific expression of androgen receptor, follicle-stimulating hormone receptor and antiMüllerian hormone type II receptor in single, isolated, human preantral follicles: relevance to polycystic ovaries. Journal of Clinical Endocrinology and Metabolism 92 1034-1040.

Roberts LM, Hirokawa Y, Nachtigal MW \& Ingraham HA 1999 Paracrinemediated apoptosis in reproductive tract development. Developmental Biology 208 110-122.

Schmidt KLT, Kryger-Baggesen N, Byskov AG \& Yding Andersen C 2005 Anti-Müllerian hormone initiates growth of human primordial follicles in vitro. Molecular and Cellular Endocrinology 234 87-93.

Silberstein T, MacLaughlin DT, Shai I, Trimarchi JR, Lambert-Messerlian G, Seiler DB, Keefe DL \& Blazar AS 2006 Müllerian inhibiting substance levels at the time of hCG administration in IVF cycles predict both ovarian reserve and embryo morphology. Human Reproduction 21 159-163.

Stubbs SA, Hardy K, Da Silva-Buttkus P, Stark J, Webber LJ, Flanagan AM, Themmen APN, Visser JA, Groome NP \& Franks S 2005 Anti-Müllerian hormone protein expression is reduced during the initial stages of follicle development in human polycystic ovaries. Journal of Clinical Endocrinology and Metabolism 90 5536-5543.

Sweeney T, Saunders PT, Millar MR \& Brooks AN 1997 Ontogeny of antiMüllerian hormone, 3-beta hydroxysteroid dehydrogenase and androgen receptor expression during ovine total gonadal development. Journal of Endocrinology 153 27-32.

Thomson RL, Buckley JD, Moran LJ, Noakes M, Clifton PM, Norman RJ \& Brinkworth GD 2009 The effect of weight loss on anti-Müllerian hormone levels in overweight and obese women with polycystic ovary syndrome and reproductive impairment. Human Reproduction $\mathbf{2 4}$ 1976-1981.

Ueno S, Kuroda T, Maclaughlin DT, Ragin RC, Manganaro TF \& Donahoe PK 1989 Müllerian inhibiting substance in the adult rat ovary during various stages of the estrous cycle. Endocrinology 125 1060-1066.

Van Roojj IAJ, Broekmans FJM, te Velde ER, Fauser BC, Bancsi LF, de Jong FH \& Themmen AP 2002 Serum anti-Müllerian hormone levels: a novel measure of ovarian reserve. Human Reproduction 17 3065-3071.

Vigier B, Picard JY, Tran D, Legeai L \& Josso N 1984 Production of antiMüllerian hormone: another homology between Sertoli and granulosa cells. Endocrinology 144 1315-1320. 
Visser JA 2003 AMH signaling: from receptor to target gene. Molecular and Cellular Endocrinology 211 65-73.

Visser JA, Mclusky A, van Beers T, Weghuis O, van Kessel AG, Grootegoed A \& Themmen APN 1995 Structure and chromosomal localization of the human anti-Müllerian hormone type II receptor gene. Biochemical and Biophysical Research Communications 215 1029-1036.

Wachs DS, Coffler MS, Malcom PJ \& Chang RJ 2007 Serum anti-Müllerian hormone concentrations are not altered by acute administration of follicle stimulating hormone in polycystic ovary syndrome and normal women. Journal of Clinical Endocrinology and Metabolism 92 1871-1874.

Weenen C, Laven JSE, von Bergh ARM, Cranfield M, Groome NP, Visser JA, Kramer P, Fauser BCJM \& Themmen APN 2004 Anti-Müllerian hormone expression pattern in the human ovary: potential implications for initial and cyclic follicle recruitment. Molecular Human Reproduction 10 77-83.
Willis D, Mason H, Gilling-Smith C \& Franks S 1996 Modulation by insulin of follicle-stimulating hormone and luteinizing hormone actions in human granulosa cells of normal and polycystic ovaries. Journal of Clinical Endocrinology and Metabolism 81 302-309.

Wilson CA, Di Clemente N, Ehrenfels C, Pepinsky RB, Josso N, Vigier B \& Cate RL 1993 MMüllerian inhibiting substance requires its $\mathrm{N}$-terminal domain for maintenance of biological activity, a novel finding within the transforming growth factor- $\beta$ superfamily. Molecular Endocrinology 7 247-257.

Received 23 September 2009

First decision 20 November 2009

Revised manuscript received 17 February 2010

Accepted 4 March 2010 